\title{
Planejamento de ações de saúde do trabalhador no SUS: uma análise dos planos municipais de saúde da VI Regional de Saúde de Pernambuco
}

\author{
Planning actions of the health of the worker in the SUS: an analysis of \\ the municipal health plans of the VI Regional de Saúde de Pernambuco
}

\section{La planificación de acciones de salud del trabajador en el SUS: un análisis de los planes municipales de salud de la VI Regional de Saúde de Pernambuco}

\section{Aureliane Cadengue Galindo | aurelianeo8galindo@gmail.com}

Universidade de Pernambuco. Garanhuns, Brasil.

Aline do Monte Gurgel | alinemgurgel@hotmail.com

Fundação Oswaldo Cruz. Fortaleza, Brasil.

\section{Resumo}

Os instrumentos de planejamento são essenciais nas instâncias gestoras do Sistema Único de Saúde (SUS) para organização de uma assistência aos trabalhadores planejada e pautada na observância de suas singularidades. Este artigo tem como objetivo analisar a inserção da Saúde do Trabalhador nos Planos Municipais de Saúde da VI Regional de Saúde de Pernambuco. Foi realizada análise documental a partir do estudo dos Planos Municipais de Saúde elaborados para o quadriênio 2014-2017. Os instrumentos foram acessados por meio do Sistema de Apoio ao Relatório de Gestão (SargSUS). A análise dos planos municipais de saúde revela baixo nível de compreensão do significado de conceitos básicos relacionados ao planejamento em saúde. Os problemas e necessidades apontados na análise situacional, de maneira geral, não são contemplados no estabelecimento das diretrizes, objetivos e metas relacionados à saúde do trabalhador. Constatou-se a existência de deficiências nos Planos Municipais de Saúde analisados no que diz respeito às ações de planejamento em saúde do trabalhador.

Palavras-chave: saúde do trabalhador; trabalho; planejamento em saúde; gestão em saúde; atenção integral à saúde. 


\title{
Abstract
}

The planning tools are essential to the decision-makers of the the Brazilian public health system, called SUS - Sistema Único de Saúde (unified health system), for organizing occupational health assistance guided by the observance of its singularities. This article aims to analyse the insertion of the contents of occupational health in municipal health plans of an health regional of Pernambuco state. A documental analysis of municipal health plans for the years from 2014 to 2017 was carried out. The tools were accessed through the Sistema de Apoio ao Relatório de Gestão - SargSUS (support system to the management report). The analysis of municipal health plans reveals little understanding of basic concepts related to health planning. The problems and necessities pointed out in the situational analysis were often neglected in the establishment of guidelines, objectives and goals related to occupational health. The study revealed the existence of deficiencies in the municipal health plans analysed in regard to the planning actions to worker health.

Keywords: occupational health; work; health planning; health management; comprehensive health care.

\section{Resumen}

Los intrumentos de planificación son esenciales en las esferas de gestión del SUS - Sistema Único de Saúde (sistema único de salud) para que la organización de asistencia a los trabajadores sea planificada y guiada de acuerdo com sus singularidades. Este artículo tiene el objetivo de analizar la inserción de la salud de los trabajadores en los planes de salud de los municipios de la VI Regional de Saúde de Pernambuco. Se realizó análisis documental a partir del estudio de los planes municipales de salud elaborados para el cuatrienio 2014-2017. Hemos hecho el acceso a los instrumentos a través del Sistema de Apoio ao Relatório de Gestão - SargSUS (sistema de apoyo a lo informe de gestión). El análisis de los planes municipales de salud revelan un bajo nivel de comprensión del significado de los conceptos básicos relacionados con la planificación de la salud. No se consideran los problemas y las necesidades señalados en el análisis de la situación, en general, para establecer las directrices, objetivos y metas relacionados con la salud de los trabajadores. Se observó la existencia de deficiencias en los planes municipales de salud analizados por lo que se refiere a la planificación de acciones de salud del trabajador.

Palabras clave: salud laboral; trabajo; planificación en salud; gestión en salud; atención integral en salud.

\begin{abstract}
Contribuição dos autores: Aureliane Cadengue Galindo contribuiu com a revisão da literatura, coleta e análise dos dados da pesquisa e redação da versão final do artigo. Aline do Monte Gurgel contribuiu com a análise dos dados, orientação, revisão do estudo e redação da versão final do artigo.
\end{abstract}

Declaração de conflito de interesses: As autoras declaram que não há quaisquer conflitos de interesse

Fontes de financiamento: Não houve financiamento

Considerações éticas: 0 estudo utilizou dados secundários de acesso público, não apresentando considerações éticas relacionadas à divulgação de dados sigilosos e/ou envolvendo animais ou seres humanos.

Histórico do artigo: Submetido: 05 jul. 2016 | Aceito:13 out. 2016 | Publicado: 23 dez.2016.

Apresentação anterior: Não houve apresentação anterior

Licença CC BY-NC atribuição não comercial. Com essa licença é permitido acessar, baixar (download), copiar, imprimir, compartilhar, reutilizar e distribuir os artigos, desde que para uso não comercial e com a citação da fonte, conferindo os devidos créditos de autoria e menção à Reciis. Nesses casos, nenhuma permissão é necessária por parte dos autores ou dos editores. 


\section{Introdução}

O conceito de saúde do trabalhador está associado à evolução da medicina do trabalho, demonstrando a insuficiência do modelo da saúde ocupacional. A saúde do trabalhador surge como resposta ao movimento social e dos trabalhadores iniciado a partir do final dos anos 1960, quando surgem as primeiras críticas à concepção limitada da saúde ocupacional e a denúncia dos efeitos negativos da medicalização. Segundo Mendes e Dias ${ }^{1}$

a saúde do trabalhador rompe com a concepção hegemônica que estabelece um vínculo causal entre a doença e um agente específico, ou a um grupo de fatores de risco presentes no ambiente de trabalho e tenta superar o enfoque que situa sua determinação no social, reduzido ao processo produtivo, desconsiderando a subjetividade.

A saúde do trabalhador busca a explicação sobre o adoecer e o morrer das pessoas a partir do estudo dos processos de trabalho, de forma articulada com o conjunto de valores, crenças e ideias, as representações sociais, e a possibilidade de consumo de bens e serviços ${ }^{1}$.

Na $1^{\text {a }}$ Conferência Nacional de Saúde do Trabalhador (CNST) foi consenso o entendimento de que a saúde dos trabalhadores extrapola os limites da saúde ocupacional, sendo resultante de um conjunto de fatores de ordem política, social e econômica² ${ }^{2}$ A saúde do trabalhador pode ser compreendida, portanto, como a expressão de forças e formas de organização que envolvem a classe trabalhadora.

No final da década de 1980, a saúde do trabalhador foi concretizada enquanto conquista social, ao ser garantida na Constituição Federal de 1988 e, posteriormente, consolidada pela Lei nº 8.080 em 1990. A saúde dos trabalhadores manifesta-se no âmago da construção de uma sociedade democrática, da conquista de direitos elementares de cidadania, da consolidação do direito à livre organização dos trabalhadores ${ }^{3}$. Desde então, as ações de saúde do trabalhador devem ser desenvolvidas pelo Estado brasileiro, sendo consideradas como competências do Sistema Único de Saúde (SUS).

A luta contra os mecanismos de desvalorização e de precariedade do trabalho, com vistas a um processo de construção e melhoria das condições de trabalho, qualidade de vida e da saúde dos trabalhadores, fez com que a área da saúde pública reconhecesse a necessidade da criação de um campo exclusivo para a saúde no trabalho, dando origem ao que foi denominado saúde do trabalhador. Essa área tem como objetivo identificar os fatores relacionados ao processo saúde-doença no campo do trabalho e formas de prevenção de agravos ${ }^{1}$.

Para Minayo-Gomez e Thedim-Costa,

O compromisso com a mudança do intrincado quadro de saúde da população trabalhadora é seu pilar fundamental, o que supõe desde o agir político, jurídico e técnico ao posicionamento ético, obrigando a definições claras diante de um longo e, presumidamente, conturbado percurso a seguir 3 .

Considerando os riscos específicos aos quais os trabalhadores estão expostos, devem ser desenvolvidas estratégias de cuidado à saúde específicas para o enfrentamento dos problemas deste grupo populacional. Diante das recentes transformações produtivas pelas quais o estado de Pernambuco tem passado, com inserção de novos riscos e novas formas de adoecer e morrer no território, planejar ações na área saúde do trabalhador revela-se fundamental para a redução dos impactos dos processos produtivos na saúde das populações4. Diante dessa conjuntura, o estudo em que se baseia o presente artigo visa analisar a inserção de ações de saúde do trabalhador nos planos municipais de saúde da VI Regional de Saúde de Pernambuco. 


\section{Aspectos históricos, conceituais e marcos regulatórios relacionados com a saúde do trabalhador}

O trabalho é considerado um dos elementos que interfere na qualidade de vida dos indivíduos e, consequentemente, nas condições de sua saúde. A expressão saúde do trabalhador faz referência ao campo do saber que busca entender as relações entre o trabalho e o processo saúde/doença. Para esse campo temático, trabalhador é toda pessoa que exerça uma atividade de trabalho, independentemente de estar inserido no mercado formal ou informal de trabalho, inclusive na forma de trabalho familiar e/ou doméstico ${ }^{5}$. Permeado por um processo dinâmico, em cada fase histórica, o modo produtivo e como os indivíduos estão inseridos nos espaços de trabalho estão diretamente relacionados com as condições de saúde do trabalhador.

A expressão surge no Brasil no bojo do Movimento pela Reforma Sanitária, que se intensificou no país a partir da década de 1980, tendo, na Reforma Sanitária Italiana, seu exemplo inspirador 6 .

Para Dias,

o momento culminante de mobilização popular pela saúde do trabalhador no Brasil dá-se na VIII Conferencia Nacional de Saúde, em 1986, e na I Conferência Nacional de Saúde do Trabalhador, também em 1986; a afirmação do movimento dentro do campo institucional acontece na IX Conferência Nacional de Saúde e na II Conferência Nacional de Saúde do Trabalhador em 19947.

A saúde do trabalhador passa a ter um novo delineamento a partir da Constituição Federal de 1988, quando insere o trabalho como direito social, e define: Artigo 200 - "Ao Sistema Único de Saúde compete, além de outras atribuições, nos termos da lei: [...] II- executar as ações de vigilância sanitária e epidemiológica, bem como as de saúde do trabalhador; [...] VIII - colaborar na proteção do meio ambiente, nele compreendido o do trabalho"s.

A Lei 8.080/90 - Lei Orgânica da Saúde que regulamentou o Sistema Único de Saúde (SUS) inclui a saúde do trabalhador no campo de atuação desse sistema, considerando o trabalho como importante fator determinante/condicionante da saúde. De acordo com a referida lei, em seu Artigo 6º , parágrafo terceiro:

Entende-se por saúde do trabalhador, para fins desta lei, um conjunto de atividades que se destina, através das ações de vigilância epidemiológica e vigilância sanitária, à promoção e proteção da saúde dos trabalhadores, assim como visa à recuperação e reabilitação da saúde dos trabalhadores submetidos aos riscos e agravos advindos das condições de trabalho ${ }^{9}$.

Em 2002, a Portaria MS/GM n ${ }^{0} 1.679$ criou a Rede Nacional de Atenção Integral à Saúde do Trabalhador no SUS. O processo de descentralização das ações de saúde vem sendo consolidado com o objetivo de organizar a rede de prestação de serviços de saúde de modo a atender às necessidades da população e aos princípios do SUS. O Decreto $\mathrm{n}^{0}$ 7.508, publicado em 2011 com a finalidade de regulamentar a Lei Orgânica de Saúde, aponta que essa descentralização deve acontecer a partir da organização regional das açõe ${ }^{10}$. No ano seguinte, a Portaria $\mathrm{n}^{0}$ 1.823, de 23 de agosto de 2012, que instituiu a Política Nacional de Saúde do Trabalhador e da Trabalhadora, trouxe elementos a serem observados nas três esferas de gestão do SUS para a atenção integral e redução da morbimortalidade oriunda dos processos produtivos nos quais os trabalhadores estão inseridos. Entre os desafios impostos por esse processo está a inclusão formal das ações de saúde do trabalhador na agenda pública da saúde. 


\section{Planejamento e gestão em saúde do trabalhador}

A assistência oferecida aos trabalhadores deve ser planejada e estar pautada na observância de suas singularidades, ou seja, por estarem sujeitos a um adoecimento específico, os trabalhadores necessitam de estratégias específicas que visem à promoção, proteção e recuperação da saúde.

Esse processo de gestão do SUS se dá por meio do Sistema de Planejamento do Sistema Único de Saúde (PlanejaSUS) que direciona as responsabilidades de cada esfera de gestão, mediante a definição de objetivos, considerando também o monitoramento e avaliação ${ }^{11}$. Assim, planejar consiste, basicamente, em decidir com antecedência o que será feito para mudar condições insatisfatórias no presente ou evitar que condições adequadas venham a deteriorar-se no futuro ${ }^{12}$.

O planejamento - e instrumentos resultantes de seu processo, como planos e relatórios - é objeto de grande parte do arcabouço legal do SUS, quer indicando processos e métodos de formulação, quer como requisitos para fins de repasse de recursos e de controle e auditoria ${ }^{13}$. A transparência do emprego de recursos é destacada pela Lei Complementar (LC) 131/2009 ${ }^{14}$, que altera a redação da Lei de Responsabilidade Fiscal (LRF), conhecida como lei da transparência, assim como pela LC 141/2012 ${ }^{15}$, que dá ênfase à visibilidade da gestão da saúde, configurando o planejamento no SUS como instrumento de transparência das ações governamentais para a sociedade.

O planejamento em saúde é uma ferramenta de gestão afirmada pelo Pacto pela Saúde, expresso no componente Pacto pela Gestão previsto inicialmente na Portaria $\mathrm{n}^{0} 399$, de 22 de fevereiro de $2006^{16}$, atualmente substituída pela Portaria $\mathrm{n}^{0} 2.135$, de 25 de setembro de $2013^{11}$, que "estabelece diretrizes para o processo de planejamento no âmbito do Sistema Único de Saúde".

Perpassando seus aspectos operacionais, o planejamento é parte de uma determinada análise de como os fatos deveriam ser e permite definir que caminhos seguir para alcançar a sua concretude. Versa ainda em definir com antecedência sobre o que fazer para transformar as condições atuais, de modo a alcançar os objetivos necessários. Os resultados do processo de planejamento devem ser expressos através de instrumentos de gestão; dentre esses, destaca-se o PMS - Plano Municipal de Saúde. A Lei no 8.142, de 28 de dezembro de 1990, que dispõe sobre a participação da comunidade na gestão do Sistema Único de Saúde e sobre as transferências intergovernamentais de recursos financeiros na área da saúde define em seu art. $4^{\mathrm{o}}$ que, como requisitos para o recebimento dos recursos provenientes do Fundo Nacional de Saúde, os municípios, estados e o Distrito Federal devem contar com plano de saúde e relatório de gestão ${ }^{17}$.

De acordo com o artigo 3 da Portaria $\mathrm{n}^{0}$ 2.135, de 25 de setembro de 2013:

O Plano de Saúde, instrumento central de planejamento para definição e implementação de todas as iniciativas no âmbito da saúde de cada esfera da gestão do SUS para o período de quatro anos, explicita os compromissos do governo para o setor saúde e reflete, a partir da análise situacional, as necessidades de saúde da população e as peculiaridades próprias de cada esfera ${ }^{11}$.

No âmbito do sistema de planejamento do SUS, este é um instrumento que, mediante realização do diagnóstico situacional, apresenta as intenções e os resultados a serem buscados no período de quatro anos, expressos em objetivos, diretrizes e metas, bem como, elemento obrigatório para o recebimento de recurso. Assim, subsidia e fortalece a gestão municipal, na medida em que deve ser apresentado, discutido e aprovado pelo Conselho Municipal de Saúde. É importante que essa ferramenta de gestão contemple ações e norteie as necessidades relacionadas à saúde do(a) trabalhador(a), contribuindo para que o SUS seja capaz de assegurar o acesso universal e a atenção integral para esses usuários. 


\section{Regionalização da saúde do trabalhador em Pernambuco}

No estado de Pernambuco, a saúde do trabalhador tem início em 1989, com a publicação da Constituição Estadual, que estabeleceu em seu artigo 166 que cabia ao estado desenvolver ações de saúde do trabalhador que dispusessem sobre a fiscalização e coordenação geral na prevenção e prestação de serviços, entre outras atividades. De acordo com o referido artigo, inciso IX, a lei objetiva garantir:

a) medidas que visem à eliminação de riscos de acidentes, doenças profissionais e do trabalho, e que ordenem o processo produtivo de modo a garantir a saúde e a vida dos trabalhadores; b) informações aos trabalhadores a respeito de atividades que comportem riscos à saúde e dos métodos para o seu controle; c) controle e fiscalização, através dos órgãos de vigilância sanitária, dos ambientes e processos de trabalho, de acordo com os riscos de saúde, garantindo o acompanhamento pelos sindicatos; d) participação dos sindicatos e associações classistas na gestão dos serviços relacionados à medicina e segurança do trabalho ${ }^{18}$.

Outro marco importante na saúde do trabalhador do estado se deu com a publicação do Decreto $\mathrm{n}^{0}$ 20.786, de 10 de agosto de $1998^{19}$, que modifica o regulamento do Código Sanitário do estado de Pernambuco. O novo código inclui a saúde do trabalhador no rol das ações a serem desenvolvidas pelo setor saúde, ratificando o papel do estado na garantia da assistência integral à saúde dos trabalhadores em todos os níveis de atenção; no fortalecimento da vigilância nos ambientes de trabalho, mediante a notificação compulsória dos acidentes de trabalho e das doenças ocupacionais, além da fiscalização dos serviços contratados, conveniados e próprios das empresas para o atendimento ao trabalhador; e na instituição de atividades educativas ${ }^{20}$.

Com a ampliação da Rede Nacional de Atenção Integral à Saúde do Trabalhador (Renast) criada pela portaria $\mathrm{n}^{0}$ 2.728, de 11 de novembro de $2009^{21}$, ocorreu em Pernambuco a adequação e a ampliação da rede por meio da implantação de nove Centros de Referência em Saúde do Trabalhador (Cerest), instituída pela Resolução CIB 1.236/2008. Foi estruturada uma rede de apoio e matriciamento para a saúde do trabalhador composta por: um Centro de Referência em Saúde do Trabalhador (Cerest) estadual e mais oito Cerest regionais (Recife, Jaboatão dos Guararapes, Cabo de Santo Agostinho, Goiana, Palmares, Caruaru, Ouricuri e Petrolina). Mais recentemente, a Resolução CIB/PE 2.613, de 21 de julho de $2014^{22}$ definiu como atribuições dos Cerest no estado de Pernambuco:

I - prestar apoio técnico, pedagógico e científico, de forma matricial, à rede SUS, orientando os profissionais nas práticas de vigilância em saúde e na atenção à saúde do trabalhador e da trabalhadora, de acordo com sua área de cobertura; II - atuar como retaguarda técnica e especializada para as ações e Serviços da rede SUS no âmbito da sua área de abrangência.

A regionalização das ações de saúde do trabalhador em Pernambuco, definida em 2008, não seguiu o Plano Diretor de Regionalização (PDR), havendo uma distribuição dos municípios entre os Cerest regionais. Nesta lógica, os treze municípios pertencentes à Regional de Saúde de Arcoverde são cobertos por três diferentes Cerest regionais. O Cerest Palmares é responsável por Manari; o Cerest Petrolina abrange os municípios de Buíque, Ibimirim, Petrolândia, Inajá, Jatobá, Tacaratu, Tupanatinga, Venturosa e Pedra; e o Cerest Ouricuri cobre os municípios de Arcoverde, Custódia e Sertânia ${ }^{20}$. 


\section{Perfil produtivo e suas implicações na saúde do trabalhador na VI Regional de Saúde de Pernambuco}

Historicamente, Pernambuco teve na agricultura sua principal atividade econômica, sendo a cana-deaçúcar o produto de maior destaque. No entanto, nas últimas três décadas houve uma mudança de cenário, e o setor de serviços passou a ser o principal elemento gerador de receitas. Atualmente o Produto Interno Bruto (PIB) estadual apresenta a seguinte distribuição: agropecuária: 4,8\%; indústria: 21,9\%; serviços: $73,3 \%^{23}$. Cada área possui vocações econômicas distintas, sendo dotadas de infraestrutura em graus variados. Cada uma das regiões tem uma cadeia produtiva dominante que impulsiona a economia local ${ }^{4}$.

A municipalização considera o território como espaço estratégico para a descentralização e estruturação das ações de saúde do trabalhador, permitindo o reconhecimento e a identificação de ocorrências de risco para a saúde, oriundos dos processos produtivos e da conjuntura das transformações nas formas de trabalho.

A Regional de Saúde de Arcoverde conta com uma população estimada em 408.604 habitantes para o ano de 2014 (IBGE). Segundo o Mapa da Sexta Região de Saúde de Pernambuco de 2012, ela integra a macrorregião de saúde 3 - Sertão, com sede em Serra Talhada, estando conformada por duas microrregiões de saúde: a X microrregião de saúde, com sede em Arcoverde, que comporta além da sede, os municípios de Buíque, Custódia, Ibimirim, Pedra, Sertânia, Tupanatinga e Venturosa; e a XI microrregião de saúde com sede em Petrolândia, incluindo os municípios de Inajá, Jatobá, Manari e Tacaratu. Sua área territorial cobre $13 \cdot 706,10 \mathrm{~km}^{2}$, estando incluídos na região de desenvolvimento do Moxotó ${ }^{24}$.

As atividades produtivas da região são diversificadas e estão distribuídas em diferentes setores produtivos. O município de Arcoverde possui maior diversidade econômica em relação aos demais, com destaque para os setores de comércio, serviços, administração pública, indústria de transformação, construção civil, agropecuária, contando ainda com a produção de artesanato, como bordados, renascença e peças de barro, entre as principais atividades econômicas.

Os demais municípios possuem expressividade nas atividades agropecuárias e de caça e pesca. Em Custódia destaca-se a caprinocultura, além dos setores da indústria, comércio e serviços. O perfil econômico de Ibimirim baseia-se na agricultura, com maior potencialidade de desenvolvimento da agropecuária leiteira, além do artesanato. Em Buíque, Tupanatinga e Sertânia destaca-se a agricultura de forma geral. Inajá apresenta expressividade nas atividades pastoris, com destaque para a bovinocultura e caprinocultura, enquanto nas atividades agrícolas predomina a produção de frutas. Petrolândia tem o rio São Francisco como fator importante para o desenvolvimento da piscicultura, assim como agricultura irrigada; na pecuária, destaca-se a caprinocultura. Essas atividades são características também do município de Jatobá, onde o rio São Francisco e o Lago de Itaparica alimentam a produção agrícola ribeirinha e projetos de irrigação. Venturosa tem a indústria de derivados do leite como importante atividade no território. Tacaratu, por sua vez, se destaca com a produção artesanal por meio da tapeçaria, cuja tecelagem é produzida em larga escala.

As atividades produtivas desempenhadas no setor da agropecuária e serviços são destaques na VI Regional de Saúde e estão relacionadas com três dos mais graves problemas de saúde enfrentados pelos trabalhadores nas últimas décadas: as intoxicações exógenas e as lesões por esforços repetitivos (LER)/ distúrbios osteomusculares relacionados ao trabalho (Dort), agravos que surgem devido às relações e à organização do trabalho cujas atividades são desempenhadas com movimentos intensos e repetitivos ou músculo estático, assim como postura e outras condições inadequadas, o que aponta a necessidade de ações de saúde que visem particularmente à prevenção desses agravos nos trabalhadores dessa região.

A Portaria GM 2728/o9 afirma que "as Secretarias Municipais de Saúde devem definir diretrizes, regular, pactuar e executar as ações de Saúde do Trabalhador no âmbito do respectivo Município ${ }^{21 "}$. Criada com o intuito de coordenar e articular as ações de promoção, prevenção e recuperação da saúde do 
trabalhador no âmbito do SUS, de maneira hierarquizada e regionalizada, a Política Nacional de Saúde do Trabalhador e da Trabalhadora - PNSTT traz como competência do gestor municipal no parágrafo 3 da Portaria $\mathrm{n}^{0}$ 1.823, de 23 de agosto de 2012:

conduzir as negociações nas instâncias municipais do SUS, visando inserir ações, metas e indicadores de saúde do trabalhador no Plano Municipal de Saúde e na Programação Anual de Saúde, a partir de planejamento estratégico que considere a Política Nacional de Saúde do Trabalhador e da Trabalhadora ${ }^{25}$.

Os processos produtivos não se distribuem de forma homogênea nos territórios, o que causa desigualdades na socialização dos riscos para a saúde das populações. Aqueles que oferecem mais risco para a saúde humana, em particular para os mais vulnerabilizados, tendem a se localizar onde a oferta de mão de obra barata é abundante, a fiscalização do cumprimento das leis é frágil e o controle social não é exercido adequadamente. Nesses territórios, os trabalhadores são os que se expõem com maior frequência e intensidade, sendo os primeiros a experimentar os impactos decorrentes das atividades produtivas 4 .

Diante da complexidade dos problemas relacionados aos processos produtivos instalados nos territórios e da necessidade da rede de saúde incorporar o cuidado integral aos trabalhadores, assumindo um compromisso a ser desempenhado pelos municípios e pelo estado com a implementação da política de saúde do trabalhador, torna-se necessário analisar o planejamento e execução de ações de saúde do trabalhador no âmbito do SUS para a garantia do cuidado integral à saúde do(a) trabalhador(a). Nesse sentido, o estudo aqui apresentado teve como objetivo analisar a inserção da saúde do trabalhador nos planos de saúde dos municípios da VI Regional de Saúde de Pernambuco.

\section{Metodologia}

Foi realizado um estudo descritivo de abordagem qualitativa mediante uma análise documental dos planos municipais de saúde (PMS) dos treze municípios que compõem a VI Regional de Saúde do estado de Pernambuco elaborados para o quadriênio 2014-2017.

Para o acesso aos instrumentos de planejamento e gestão, foi utilizado o Sistema de Apoio ao Relatório de Gestão (SargSUS), disponível no portal da saúde SUS ${ }^{26}$. A Portaria GM/MS 2.135 de 2013 estabelece que os planos de saúde devem ser disponibilizados em meio eletrônico no Sargsus, uma vez que, declarada a sua existência, sua postagem passa a ser obrigatória, devendo o mesmo ser inserido como anexo ao Relatório Anual de Gestão (RAG) ${ }^{11}$.

Os PMS foram extraídos do SargSUS em 16 de setembro de 2015. Do total de treze (13) municípios que compõem a VI Regional de Saúde, onze (11) tiveram seus planos de saúde analisados. Os municípios de Manari e Pedra não foram incluídos no estudo em decorrência de seus respectivos PMS referentes ao quadriênio 2014-2017 não terem sido disponibilizados no sistema de informação utilizado para a coleta de dados.

Para a coleta dos dados secundários, oriundos das pesquisas bibliográficas, foram utilizados periódicos indexados, publicações oficiais do Ministério da Saúde, legislações federais, estaduais e municipais, livros, monografias, dissertações, teses, jornais e revistas de difusão. Esses dados foram utilizados para descrever o processo de planejamento em saúde e da política de saúde do trabalhador. 
Os planos foram analisados quanto aos seguintes elementos:

a) Momentos de elaboração: análise situacional e formulação de objetivos, diretrizes e metas para saúde do trabalhador.

b) Atenção integral: presença de elementos que visem estruturar a saúde do trabalhador nas redes de assistência existentes no município e ou região de saúde, bem como produção dos serviços de saúde, voltados para i) atenção básica; ii) atenção especializada e rede de laboratórios e de serviços de apoio diagnóstico (incluindo assistência de fisioterapia, centros de referência, diagnose, sistema de informações, programas de saúde, serviços de referência e contrarreferência, incorporações tecnológicas); iii) vigilância em saúde (vigilâncias sanitária, epidemiológica, ambiental, do trabalhador e controle de zoonoses); iv) assistência hospitalar; v) assistência de urgência e emergência: (incluindo unidade de Pronto Atendimento, Serviço Móvel de Urgência e Emergência e organização, funcionamento e mecanismos de regulação para ações de saúde do trabalhador); vi) assistência farmacêutica.

c) Gestão de saúde: análise da estrutura, organização e operacionalização do processo de planejamento, bem como a sua interação como o centro de decisão, considerando i) a descentralização/ regionalização (presença de cooperação entre as esferas de governo, estratégia de coordenação de promoção de equidade, atividades no âmbito da comissão intergestores, funcionamento e participação do colegiado de gestão regional, o termo de compromisso de gestão, desenho de redes de regionalização de atenção à saúde); ii) o financiamento (existência de transferências entre as esferas de gestão, gasto público total, execução orçamentária e financeira, fundo de saúde e critérios e regulamentação do financiamento para a saúde do trabalhador); iii) participação social (ações voltadas para o fortalecimento e o controle social em saúde do trabalhador, com criação de comissões intersetoriais de saúde do trabalhador no âmbito dos Conselhos de saúde, saúde do trabalhador nas conferências de saúde e conferências de saúde temáticas).

d) Após a leitura e análise os dados foram agrupados em tabelas síntese, evidenciando as presenças e ausências de acordo com as categorias definidas.

O estudo utilizou dados secundários de acesso público, tendo seguido os padrões éticos preconizados pela Resolução No 466 de 12 de dezembro de 2012.

\section{Resultados}

\section{Análise situacional e formulação de objetivos, diretrizes e metas para a saúde do trabalhador}

A análise situacional define as prioridades de saúde a serem abordadas, as intenções e os resultados a serem buscados pelo município em um período de quatro anos, expressos em objetivos, diretrizes e metas.

Pode-se observar que apenas seis dos onze municípios da VI Regional de Saúde estudados estabeleceram diretrizes, objetivos e metas relacionados à saúde do trabalhador em seus respectivos planos de saúde: Arcoverde, Ibimirim, Jatobá, Sertânia, Tacaratu e Venturosa (Quadro 1). 
Quadro 1 - Objetivos, diretrizes e metas para a saúde do trabalhador constantes nos planos de saúde dos municípios da VI Regional de Saúde de Pernambuco referentes ao quadriênio de 2014-2017

\begin{tabular}{|c|c|c|c|}
\hline Município & Diretriz & Objetivo & Metas \\
\hline \multirow{7}{*}{ Arcoverde } & \multirow{7}{*}{$\begin{array}{l}\text { Trabalhador } \\
\text { assistido na saúde }\end{array}$} & \multirow{7}{*}{$\begin{array}{l}\text { Implantar a assistência } \\
\text { e acolhimento dos } \\
\text { trabalhadores nos serviços } \\
\text { de saúde, com o intuito de } \\
\text { identificar precocemente os } \\
\text { fatores de risco, implantar } \\
\text { ações de prevenção e } \\
\text { promoção e melhorar os } \\
\text { indicadores de saúde }\end{array}$} & $\begin{array}{l}\text { Realizar anualmente atividades } \\
\text { educativas para conscientização dos } \\
\text { empregadores sobre o cumprimento } \\
\text { da legislação trabalhista, em } 100 \% \text { das } \\
\text { Unidades Básicas de Saúde Fluviais } \\
\text { (UBSF) }\end{array}$ \\
\hline & & & $\begin{array}{l}\text { Implantar uma unidade Cerest no } \\
\text { município }\end{array}$ \\
\hline & & & $\begin{array}{l}\text { Implantar ações de saúde do trabalhador } \\
\text { em } 100 \% \text { das UBSF }\end{array}$ \\
\hline & & & $\begin{array}{l}\text { Implantar programa de cuidado com os } \\
\text { profissionais da saúde em } 100 \% \text { das } \\
\text { UBSF }\end{array}$ \\
\hline & & & $\begin{array}{l}\text { Atualizar } 100 \% \text { o calendário vacinal dos } \\
\text { trabalhadores da saúde }\end{array}$ \\
\hline & & & $\begin{array}{l}\text { Realizar oficina de atualização para } \\
100 \% \text { dos trabalhadores da saúde das } \\
\text { UBSF }\end{array}$ \\
\hline & & & $\begin{array}{l}\text { Garantir } 100 \% \text { de assistência dos } \\
\text { profissionais do Núcleo de Apoio à Saúde } \\
\text { da Família (Nasf). }\end{array}$ \\
\hline Buíque & Ausente & Ausente & Ausente \\
\hline Custódia & Ausente & Ausente & Ausente \\
\hline Ibimirim & $\begin{array}{l}\text { Proteção do } \\
\text { direito de acesso à } \\
\text { educação básica, } \\
\text { profissionalizante e } \\
\text { oportunidades de } \\
\text { emprego e renda }\end{array}$ & $\begin{array}{l}\text { Implantar o programa saúde } \\
\text { do trabalhador }\end{array}$ & $\begin{array}{l}\text { Fiscalizar } 100 \% \text { das empresas uma vez } \\
\text { por ano }\end{array}$ \\
\hline Inajá & Ausente & Ausente & Ausente \\
\hline Jatobá & $\begin{array}{l}\text { Inexistência de } \\
\text { serviço referencial } \\
\text { para a saúde do } \\
\text { trabalhador }\end{array}$ & $\begin{array}{l}\text { Implantar serviço de } \\
\text { referência em saúde do } \\
\text { trabalhador e garantir serviço } \\
\text { de epidemiologia voltado } \\
\text { para a saúde do trabalhador }\end{array}$ & $\begin{array}{l}\text { Implantar serviço até dezembro } \\
2015 \text { e implementar, na vigilância } \\
\text { epidemiológica, serviços voltados para a } \\
\text { saúde do trabalhador até } 2017\end{array}$ \\
\hline Petrolândia & Ausente & Ausente & Ausente \\
\hline
\end{tabular}




\begin{tabular}{|c|c|c|c|}
\hline Município & Diretriz & Objetivo & Metas \\
\hline \multirow{5}{*}{ Sertânia } & \multirow{5}{*}{$\begin{array}{l}\text { Implantar a } \\
\text { atenção integral } \\
\text { à saúde do } \\
\text { trabalhador com } \\
\text { ações nos níveis } \\
\text { de assistência, } \\
\text { tratamento, } \\
\text { recuperação, } \\
\text { reabilitação e } \\
\text { prevenção, visando } \\
\text { promover a saúde } \\
\text { do trabalhador } \\
\text { no município e na } \\
\text { região }\end{array}$} & \multirow{5}{*}{$\begin{array}{l}\text { Promoção da saúde do } \\
\text { trabalhador atendendo à } \\
\text { Portaria da Rede Nacional } \\
\text { de Atenção Integral a Saúde } \\
\text { do Trabalhador (Renast) - } \\
2437 / 2005 \text { que estabelece a } \\
\text { ampliação e o fortalecimento } \\
\text { da saúde do trabalhador no } \\
\text { âmbito do SUS }\end{array}$} & $\begin{array}{l}\text { Aumentar as buscas e notificações } \\
\text { de acidente do trabalho e doenças } \\
\text { do trabalho através do Sistema de } \\
\text { Informações de Agravo de Notificações } \\
\text { (Sinan Net) no período de } 2014 \text { a } 2017\end{array}$ \\
\hline & & & $\begin{array}{l}\text { Realizar o diagnóstico situacional visando } \\
\text { conhecer a situação real epidemiológica } \\
\text { da saúde do trabalhador no município no } \\
\text { período de } 2014 \text { a } 2017\end{array}$ \\
\hline & & & $\begin{array}{l}\text { Melhorar, através do estabelecimento de } \\
\text { fluxos e protocolos, a atenção integral } \\
\text { dos trabalhadores usuários do SUS no } \\
\text { período de } 2014 \text { a } 2017\end{array}$ \\
\hline & & & $\begin{array}{l}\text { Capacitar profissionais de saúde de } \\
\text { hospitais públicos e privados para } \\
\text { notificarem os agravos constantes na } \\
\text { Port. } 777 / 2004 \text { no período de } 2014 \text { a } \\
2017\end{array}$ \\
\hline & & & $\begin{array}{l}\text { Realizar atividades de orientação para } \\
\text { prevenção de LER/Dort, ginástica } \\
\text { laboral de preparação, compensação e } \\
\text { relaxamento no período de } 2014 \text { a } 2017\end{array}$ \\
\hline Tupanatinga & Ausente & Ausente & Ausente \\
\hline Tacaratu & $\begin{array}{l}\text { Redução dos riscos } \\
\text { e agravos à saúde } \\
\text { da população, por } \\
\text { meio das ações } \\
\text { de promoção e } \\
\text { vigilância em saúde }\end{array}$ & $\begin{array}{l}\text { Fortalecer a promoção e } \\
\text { vigilância em saúde }\end{array}$ & $\begin{array}{l}\text { Ampliar em } 30 \% \text { o número notificado } \\
\text { de casos de doenças ou agravos } \\
\text { relacionados ao trabalho }\end{array}$ \\
\hline Venturosa & $\begin{array}{l}\text { Implementar } \\
\text { atividades de } \\
\text { vigilância em saúde }\end{array}$ & $\begin{array}{l}\text { Garantir a realização das } \\
\text { ações de vigilância em } \\
\text { saúde, visando minimizar } \\
\text { os riscos enfrentados pela } \\
\text { população, disponibilizando } \\
\text { recursos para identificação } \\
\text { de problemáticas e } \\
\text { consequentes respostas } \\
\text { eficazes }\end{array}$ & $\begin{array}{l}\text { Implantar serviços de notificação de } \\
\text { agravos relacionados ao trabalhador de } \\
\text { saúde em } 100 \% \text { das unidades de saúde }\end{array}$ \\
\hline
\end{tabular}

Fonte: Elaborado pelas autoras (2016)

Percebe-se que não há um entendimento claro do significado da conceituação dos termos 'diretriz', 'objetivo' e 'meta' por parte dos municípios. A viabilidade de concretização desses três elementos fundamentais do plano depende, sistematicamente, de como são elaboradas e de como se relacionam. As diretrizes pressupõem uma linha de ação a ser seguida, que necessita de objetividade para delimitar as prioridades do plano. Os objetivos devem denotar coerência, uma vez que expressam a tomada de decisão frente aos problemas identificados na análise situacional. Já as metas devem possibilitar a concretização do objeto no tempo, devendo ser expressas quantitativamente de modo que sua mensuração seja possível, características não observadas nos planejamentos de Sertânia e Jatobá. 
Os municípios destacam em seus PMS outras proposições relacionadas à saúde do trabalhador além das especificadas no Quadro 1, a exemplo o município de Arcoverde, que aponta como problemas a serem enfrentados a redução de notificações de casos de doenças ou agravos relacionados ao trabalho, ausência da oferta de um horário opcional para o trabalhador da rede de saúde, ausência de educação em saúde para idosos e trabalhadores, falta de registro/notificação dos acidentes de trabalho, ausência de um núcleo de saúde do trabalhador, e ausência de ações específicas voltadas para o trabalhador da saúde.

Para a saúde do trabalhador, Jatobá apresenta estratégias para os objetivos citados, como elaborar projeto para o Ministério da Saúde (MS), elaborar um plano de ação para saúde do trabalhador, desenvolver ações educativas para a prevenção e a redução de danos, elaborar documento normativo e capacitar profissionais da rede. Sertânia vislumbra implantar projetos como um núcleo de vigilância de saúde do trabalhador, implementar um um ambulatório de saúde do trabalhador, serviços sentinelas no município, e ações de vigilância sanitária, epidemiológica e ambiental com o núcleo de vigilância de saúde do trabalhador.

Ibimirim visa à ampliação do número de programas de saúde implantados voltados para auxiliar na garantia do acesso à educação e ao trabalho, tendo como indicadores de resultado a existência de ato normativo/legal criando e disciplinando o funcionamento do programa; a existência na Lei Orçamentária Anual (LOA) de recursos financeiros a serem alocados para a execução de ações relacionadas à saúde do trabalhador e o número absoluto de ações de fiscalização das empresas para garantir o fornecimento de EPI (equipamento de proteção individual) para trabalhadores.

Tacaratu prevê, além do destacado anteriormente, capacitar e sensibilizar os profissionais da rede municipal de saúde sobre a importância das notificações, desenvolver ações de prevenção, promoção e vigilância em saúde do trabalhador, capacitar profissionais em notificação de acidentes graves de trabalho, desenvolver ações de prevenção, promoção e vigilância em saúde do trabalhador.

Venturosa insere suas diretrizes, objetivos e metas segundo blocos de financiamento, sendo a saúde do trabalhador citada na vigilância epidemiológica. Ainda em seu texto aponta a ausência de registro de casos de doenças ou agravos relacionados ao trabalho, ausência de unidade sentinela para realizar as atividades de saúde do trabalhador.

\section{Atenção integral}

Em relação à atenção integral à saúde do trabalhador verifica-se que apenas o município de Arcoverde pontuou a necessidade de atendimento aos trabalhadores, apontando como meta a implantação de atendimento no terceiro turno em 50\% dos serviços de saúde do município, com vistas a abranger a população de trabalhadores. No eixo da média e alta complexidade, o município expõe como meta a contratação de enfermeiro com especialização na área de saúde do trabalhador, fazendo assim referência à rede especializada.

Os demais municípios não apresentaram em seus planos de saúde metas e ações em saúde do trabalhador. Adicionalmente, o município de Tacaratu aponta em seu PMS que o setor de vigilância em saúde organizase da seguinte forma: vigilância epidemiológica e centro de zoonoses, programa de endemias e chagas, programa DST/Aids e hepatites virais, núcleo de prevenção de acidentes e violência, programa nacional de imunizações (PNI), centro de referência à saúde do trabalhador (Cerest).

\section{Gestão de saúde}

Arcoverde estabelece a meta de implantação de um núcleo de saúde e segurança do trabalho. Quanto ao financiamento, o município de Ibimirim aborda a necessidade de assegurar recursos através da LOA para que o programa saúde do trabalhador seja implantado, com transferências do SUS e do tesouro municipal, especificando no PMS meta orçamentária para o quadriênio. 
Os municípios apontam as fragilidades e necessidades do Conselho Municipal de Saúde quanto à estrutura e qualificação, bem como, sua atuação e contribuição para a construção do plano municipal de saúde. Buíque evidencia propostas aprovadas na VI Conferência em 2013 para o referido PMS voltadas ao fortalecimento e ao controle social da saúde do trabalhador. Para a acessibilidade ao serviço de saúde com qualidade o município visa oferecer equipamentos de proteção individual (EPI) aos agentes comunitários de saúde (preconizados pelo MS) e para o fortalecimento da rede de saúde - qualificação, valorização de democratização das relações do trabalho e da atenção à saúde -, destaca-se a criação do programa saúde do trabalhador e da gestão do trabalho e educação.

\section{Discussão}

Cada município dispõe de autonomia para determinar as linhas gerais do processo de construção do seu plano municipal de saúde de acordo com os princípios e diretrizes adotados na legislação básica do SUS. Esse instrumento de gestão é baseado em um levantamento da análise situacional da saúde em seus diversos aspectos para subsidiar a identificação, formulação e enfatizar os problemas em uma determinada realidade.

A análise dos planos municipais de saúde revela pouco nível de compreensão do significado de conceitos básicos para elaboração dos instrumentos de gestão pelos municípios avaliados. Observou-se que cada município elabora o respectivo instrumento de gestão de forma heterogênea, na qual em geral o conteúdo expresso relativo à saúde do trabalhador não segue a estrutura organizativa proposta para os planos de saúde, assim como outras ações almejadas não são expostas como uma meta a ser atingida para resolução de problemas. Esses resultados se assemelham aos encontrados por Saliba e colaboradores ${ }^{27}$, que identificaram em seu estudo que "os planos de saúde não se apresentavam de forma estruturada, clara e definida”. Segundo os autores, os objetivos gerais e específicos, que deveriam estar descritos em separado, eram citados de forma dispersa em todo o plano.

Essas fragilidades indicam a necessidade da adoção de estratégias como oficinas, com o intuito de apoiar os municípios na estruturação de seus instrumentos de planejamento e gestão. No ano de 2015 foi publicado o novo Manual de Planejamento do SUS ${ }^{28}$, ferramenta importante que pode subsidiar o direcionamento do planejamento, a capacitação das equipes e fornecer orientações aos gestores da saúde.

Outras barreiras que dificultam a concretização da implantação das ações em saúde do trabalhador pelos municípios são evidenciadas nos estudos de Vaz e colaboradores ${ }^{29}$. Dentre elas, destacam-se os problemas relacionados ao déficit na organização governamental quanto à implantação das ações em saúde do trabalhador, à deficiência no setor de recursos humanos e materiais e à pouca capacidade de reação do trabalhador. Daldon e Lancman ${ }^{30}$ relatam que, hoje, parece haver um retrocesso e alguns serviços de saúde do trabalhador têm sido compelidos a ações fragmentadas, sem que haja um planejamento dessas ações e sem que seja avaliado o alcance do trabalho que vem sendo realizado, correndo assim o risco de se distanciarem de seus reais objetivos. Para Mélo ${ }^{20}$, alguns autores afirmam que a saúde do trabalhador tem sido colocada à margem das políticas do SUS devido à baixa articulação intersetorial, ao não reconhecimento do trabalho como determinante do processo saúde-doença e à pouca relevância dada ao tema pelos gestores no direcionamento das ações do SUS.

Em relação ao eixo que trata da análise situacional e formulação de objetivos, diretrizes e metas em saúde do trabalhador, o município de Arcoverde destaca como meta a intenção de realizar anualmente atividades educativas para conscientização dos empregadores sobre o cumprimento da legislação trabalhista. Todavia, a Consolidação das Leis do Trabalho (CLT) ${ }^{31}$, publicada no Decreto-Lei n. ${ }^{0} 5.452$, de $1^{0}$ de maio de 1943 prevê em seu artigo 626 que "incumbe às autoridades competentes do Ministério do Trabalho e Emprego (MTE), ou àquelas que exerçam funções delegadas, a fiscalização do fiel cumprimento das normas de 
proteção ao trabalho". Este fato demonstra a dificuldade do município de compreender e diferenciar as atribuições do Ministério da Saúde e do Ministério do Trabalho em relação à saúde do trabalhador.

Quanto às metas para saúde do trabalhador, Buíque, Custódia, Inajá, Petrolândia e Tupanatinga não apresentam qualquer proposição a ser concretizada. Não é possível mensurar as metas destacadas nos PMS dos municípios de Jatobá e Sertânia, uma vez que elas não são expressões quantitativas de um objetivo, e, portanto, não podem ser mensuradas no tempo.

Tacaratu e Venturosa não estabelecem diretrizes direcionadas à saúde do trabalhador; já o município de Jatobá aponta um problema como diretriz e não uma linha de ação ou estratégia específica. Essa categoria trata de linhas de ação a serem seguidas de forma objetiva, cujo enunciado retrata uma estratégia geral e prioridade do PMS. Com o objetivo de implantar serviço de referência em saúde do trabalhador, o município de Jatobá lança algumas estratégias como, por exemplo, desenvolver ações educativas para a prevenção e a redução de danos, não ficando claro seu direcionamento, que pode estar voltado para a vigilância de risco à saúde do trabalhador ou para a política de prevenção ao álcool e outras drogas.

Em relação à atenção integral, os planos analisados não apresentam, de forma sistêmica, elementos que visem estruturar a saúde do trabalhador nas redes de assistência existentes no município e ou na região de saúde, bem como a produção dos serviços de saúde voltados para ações de promoção, vigilância, prevenção e assistência.

No eixo de atenção integral, o plano de Arcoverde destaca como meta a implantação de atendimento noturno em metade dos serviços de saúde do município, com vistas a abranger a população de trabalhadores. Entretanto, essa estratégia é voltada para o fortalecimento da política de saúde do homem, medida que exclui a população feminina.

Com vistas ao fortalecimento da rede de assistência, Arcoverde enfatiza ainda a previsão da implantação de um Cerest, buscando apoiar o desenvolvimento de ações em saúde do trabalhador. De acordo com a Portaria $\mathrm{n}^{0}$ 2.728, de 11 de novembro de 2009, que "dispõe sobre a Rede Nacional de Atenção Integral à Saúde do Trabalhador (RENAST) ”21 e com a política nacional de saúde do trabalhador e da trabalhadora ${ }^{25}$, os Cerest não possuem função assistencial, devendo atuar como referências técnicas e como provedores de apoio matricial aos municípios, denotando o baixo nível de conhecimento dessa política por parte dos municípios. Conforme apontado anteriormente, os municípios da VI Regional de Saúde são cobertos por três Cerest regionais, sendo que nenhum deles constitui-se como sede desses centros, o que contrapõe a informação constante no PMS de Tacaratu quando relata que o setor de vigilância em saúde conta com um Cerest.

No que se refere à vigilância, embora problemas e necessidades sejam destacados na análise situacional de modo a permitir a definição das medidas a serem adotadas, por vezes estas não são contempladas no estabelecimento das diretrizes, objetivos e metas nos PMS, evidenciando o desconhecimento de sua finalidade e importância para a sua resolução. Este fato pode ser observado no instrumento de Arcoverde, que abordou em seu plano a ausência de núcleo de saúde do trabalhador e a redução de notificações de agravos relacionados à saúde do trabalhador e subnotificação de acidentes de trabalho sem, contudo, propor ações e metas para mitigar o problema.

O registro das doenças e agravos relacionados ao trabalho no Sistema de Informação de Agravos de Notificação (Sinan) compete ao município, cabendo aos profissionais de saúde (municipais, estaduais ou federais) identificar casos suspeitos ou confirmados e reportar ao município para que por ele seja realizada a investigação e alimentado o Sinan. As notificações são indicadores importantes dos perigos e nocividades aos quais o trabalhador está exposto, e o sub-registro das doenças e agravos relacionados ao trabalho apontam a necessidade de fortalecer o sistema de registro de informações em saúde, com treinamento dos profissionais que compõem a rede, incluindo os responsáveis pela sua identificação e notificação. Albuquerque e colaboradores ${ }^{32}$ reforçam que, além do incremento na qualidade, são necessárias ações para aumentar o número de casos notificados, 
incluindo estratégias como a busca ativa de casos e ações de educação permanente junto a profissionais de saúde para diagnóstico de intoxicações crônicas.

Ainda sobre o registro de doenças e agravos relacionados ao trabalho, Tacaratu aponta como meta a ampliação em 30\% do número de notificações, identificando o sub-registro como um problema em seu território.

A escassez e a inconsistência das informações sobre a real situação de saúde dos trabalhadores dificultam a definição de prioridades para as políticas públicas, o planejamento e a implementação das ações de saúde do trabalhador, além de privar a sociedade de subsídios importantes para a melhoria das condições de vida e trabalho ${ }^{33}$.

Venturosa, em sua análise situacional, também cita problemas a serem enfrentados na vigilância em saúde, mencionando a ausência de unidade sentinela para realizar as atividades de saúde do trabalhador. Entretanto, a ausência de unidades sentinela não impossibilita a realização de ações de saúde do trabalhador, tampouco desobriga o município de realizá-las, dado que elas devem acontecer em todos os níveis de atenção, conforme preconizado pela política de saúde do trabalhador e da trabalhadora e não somente na assistência, que é o nível de atenção em que se inserem, hoje, as unidades sentinela.

De acordo com a Portaria $\mathrm{n}^{0}$ 1.271, de 6 de junho de 2014, que "Define a Lista Nacional de Notificação Compulsória de doenças, agravos e eventos de saúde pública nos serviços de saúde públicos e privados em todo o território nacional", a notificação compulsória é obrigatória para os médicos, outros profissionais de saúde ou responsáveis pelos serviços públicos e privados de saúde, que prestam assistência ao paciente ${ }^{34}$. Em relação à saúde do trabalhador, são de notificação compulsória universal (em todo e qualquer estabelecimento de saúde, sentinela ou não) os acidentes de trabalho graves (fatais, com mutilações e com crianças e adolescentes), além dos acidentes de trabalho com exposição a material biológico e as intoxicações exógenas relacionadas ao trabalho. Adicionalmente, os acidentes de trabalho graves são considerados de notificação compulsória imediata, devendo o seu registro ser realizado em até 24 horas após a tomada de conhecimento do agravo ${ }^{34}$. Dessa forma, a notificação compulsória desses agravos prescinde de unidades sentinela específicas para este serviço.

Para Teixeira e Teixeira ${ }^{35}$, o estabelecimento de uma lista de doenças de notificação pressupõe a utilização sistemática dos dados para orientar medidas de intervenção. Nesse sentido, é requerida a capacitação técnicooperacional dos órgãos responsáveis pela vigilância epidemiológica, em todos os níveis, para o processamento, análise e disseminação de informações decorrentes da notificação. Segundo Baratieri e outros ${ }^{36}$, a Secretaria de Saúde local, com o apoio de instituições como Conselho de Saúde, Secretaria Estadual de Saúde, entre outras, possui a responsabilidade de definir a estratégia organizacional para tratar da saúde do trabalhador. Todavia, os planos de saúde analisados neste artigo não evidenciam um conjunto organizado de iniciativas com o intuito de estruturar sistematicamente a atenção à saúde dos trabalhadores e trabalhadoras.

Com imprecisão na formulação das diretrizes, que se confundem com premissas concernentes à gestão do trabalho, Ibimirim propõe a implantação de um programa de saúde do trabalhador voltado para garantir o acesso à educação básica, profissionalizante e oportunidades de emprego e renda, evidenciando o equívoco no entendimento dos objetivos da PNSTT e uma falta de concordância das intenções expressas na diretriz, objetivo e metas. Adicionalmente, a meta proposta no plano de Ibimirim, além de não possuir relação com a diretriz proposta, visa fiscalizar empresas para garantir o fornecimento de EPI para os trabalhadores, ação que não compete ao SUS e sim ao Ministério do Trabalho e Emprego (MTE). A Norma Regulamentadora 6 do MTE (NR 6) ${ }^{37}$ aponta que "a empresa é obrigada a fornecer aos empregados, gratuitamente, EPI adequado ao risco, em perfeito estado de conservação e funcionamento, cabendo ao órgão regional do MTE fiscalizar e orientar quanto ao uso adequado e a qualidade do EPI”. Exigir seu uso é obrigação da empresa e as fiscalizações de rotina são elaboradas pelos profissionais internos de segurança do trabalho e/ ou membros da Comissão Interna de Prevenção de Acidentes (Cipa) ou seus encarregados ${ }^{37}$.

Agestão de saúde visa analisar a estrutura, organização e operacionalização do processo de planejamento, bem como a sua interação como centro de decisão. Constata-se que esses fatores encontram-se fragilizados 
na VI Regional de Saúde, não sendo reconhecidos pelos municípios como primordiais para garantir a integralidade de ações de assistência e vigilância em saúde do trabalhador. Arcoverde estabelece a meta de implantação de um núcleo de saúde e segurança do trabalho, sendo esta ação, entretanto, concernente à política de gestão de pessoas relacionada à medicina ocupacional, cujo planejamento e execução são garantidos pela legislação trabalhista, não estando previsto na política de saúde do trabalhador.

Cabe ressaltar a importância das instâncias de participação e controle social do SUS, por meio das conferências e Conselhos de Saúde, uma vez que o controle social éfundamental para a construção e efetivação dessas ações. Nos PMS, alguns municípios apontam a sua participação, porém ela não é observada como parte integrante dos Conselhos de Saúde ou como intenção de criação da comissão intersetorial de saúde do trabalhador (Cist). A Resolução CNS nº 493, de 07 de novembro de 2013, determina que os Conselhos de Saúde nos âmbitos estadual, distrital e municipal promovam a criação da $\mathrm{Cist}^{38}$, visto que a participação dos trabalhadores é fundamental na identificação dos fatores de riscos existentes nos ambientes e processos de trabalho, assim como no reconhecimento das repercussões sobre o processo saúde-doença.

Outra fragilidade identificada é a falta de informação quanto à disponibilidade de recursos, resultado também encontrado no estudo de Saliba e colaboradores ${ }^{27}$, que evidenciou que os planos analisados apresentavam quadro de metas; porém, a questão das estimativas de gastos para o alcance dessas metas não foi abordada, ocorrendo apenas citação das fontes de capacitação de recursos, como recursos municipais e estaduais.

Segundo a Política Nacional de Saúde do Trabalhador e da Trabalhadora - PNASTT, as ações de saúde do trabalhador a serem desenvolvidas deverão contar com a respectiva previsão orçamentária, definida nos planos e nas programações anuais de saúde, nas três esferas de gestão do SUS ${ }^{25}$. Teixeira e Teixeira ${ }^{35}$ apontam que o fluxo adequado, contínuo e permanente de recursos financeiros para o provimento das referidas ações constitui pré-condição para a resolução de inúmeros problemas de saúde da população assistida. O financiamento é de competência dos municípios, estados e da União, entretanto, percebese que ele não tem sido evidenciado de modo adequado e permanente em seus orçamentos. Baratieri e colaboradore ${ }^{36}$ concluem que o incentivo para a implantação das ações nessa área é pequeno ou muitas vezes inexistente, e que o financiamento das ações de saúde do trabalhador no SUS é uma questão complexa e ainda não bem resolvida.

A fragilidade do planejamento pela gestão municipal de saúde pode ser novamente constatada no plano municipal de saúde de Jatobá quando descreve

A cultura do planejamento ainda não está incorporada à rotina de trabalho dos diversos setores da Secretaria. O setor se encarrega da elaboração do Plano Municipal de Saúde, do Relatório de Gestão Anual e de elaboração de planos e projetos setoriais que são demandados pelas diversas áreas técnicas do Ministério da Saúde. A programação anual de saúde é fragmentada e atende, principalmente, às demandas da SESPE/GERES. Não há monitoramento e avaliação periódicos dos indicadores de saúde pactuados. Não há avaliação de resultados. Pretende-se em 2014 contratar um profissional especifico para realizar apoio no planejamento do SUS municipal ${ }^{26}$

Barros, Piola e Vianna ${ }^{39}$ apontam que a criação por lei da obrigatoriedade de apresentação de um plano de saúde pelos municípios não garante que o processo de planejamento seja incorporado pelas secretarias municipais de saúde que assumem a gestão do sistema. É possível que o planejamento faça parte do cotidiano da gestão nos municípios onde existe melhor estrutura organizativa com quadros técnicos capacitados e que estejam mais conscientes das vantagens contidas na organização para a ação. A saúde do trabalhador, por sua vez, possui algumas particularidades que podem tornar complexa a sua efetiva implantação, como o desconhecimento de muitos gestores do SUS quanto à execução e ações de saúde do 
trabalhador; os entraves políticos no âmbito municipal, principalmente em relação às ações de vigilância, resultando na falta de investimento nesse campo por parte dos gestores; o contexto social da tensão capital e trabalho; o despreparo de alguns profissionais de saúde para desenvolver ações na área; entre outros. Por esses motivos, talvez a saúde do trabalhador, apesar de estar entre as prioridades do Pacto pela Vida, seja uma das áreas de maior defasagem em relação à sua implantação no SUS ${ }^{40}$.

Fica evidente a necessidade de fortalecer o compromisso do município relativo à importância dos instrumentos de planejamento para a garantia e oferta de ações e serviços de saúde para todos os segmentos da sociedade, particularmente para grupos populacionais vulnerabilizados como os de trabalhadores.

\section{Conclusão}

Diante do processo de descentralização das ações de saúde atualmente evidenciado no país, a organização da rede de prestação de serviços de saúde, em conformidade com os princípios e diretrizes do SUS, como a universalidade, hierarquização, equidade e integralidade da assistência, configuram-se como um importante desafio enfrentado pelos municípios e estados. Neste contexto, torna-se fundamental avaliar a implantação da gestão em saúde do trabalhador (ST) no âmbito do SUS, considerando a necessidade de sua implementação nos municípios da VI Regional de Saúde.

O estudo aqui apresentado constatou a existência de deficiências nos planos municipais de saúde analisados frente às ações de planejamento em saúde do trabalhador. A ST é pouco apreciada pelos municípios da VI Regional de Saúde no referido instrumento de gestão, onde o tema por vezes é inserido no documento de forma não sistematizada.

As fragilidades e necessidades apontadas na analise situacional nem sempre são contempladas nas diretrizes, objetivos e metas como intenções e ações a serem implementadas, percebendo-se também, em alguns planos, a falta de compreensão das definições desses elementos. Evidencia-se ainda o desconhecimento em relação às competências do município no que diz respeito às suas responsabilidades em relação à saúde do trabalhador. Há desconhecimento em relação à Renast e sua estruturação, assim como da própria PNSTT.

Pode-se concluir que a capacitação dos envolvidos no planejamento também é imprescindível para estruturar adequadamente o planejamento das estratégias de modo a enfrentar os problemas de saúde, delineando ações frente às necessidades existentes em saúde do trabalhador. São evidentes também os problemas de gestão para implementação de ações efetivas quando da ausência de elementos que visem qualificar a saúde do trabalhador nas redes de assistência existentes, com estruturação e qualificação das práticas para atender às demandas de ST de maneira integral e resolutiva, fator que exige não só compromisso e empenho a ser assumido por todos os gestores e instâncias, como também a participação da sociedade civil.

É necessário reconhecer que a publicação da Política Nacional de Saúde do Trabalhador e da Trabalhadora foi um avanço importante no SUS, sendo o planejamento uma importante estratégia para o reconhecimento e materialização da referida política. Para tanto se faz necessário que os municípios conheçam na íntegra a PNASTT, de modo a organizar sua atuação de acordo com o que lhes compete, tendo em vista que o desenvolvimento de ações de ST está diretamente relacionado com a melhoria da qualidade de vida dos indivíduos e da sociedade como um todo. Investir na promoção da saúde da classe trabalhadora é fator primordial para intervenção nos fatores riscos que interferem na sua saúde e no desempenho de suas atividades laborais. 


\section{Referências}

1. Mendes R, Dias EC. Da medicina do trabalho à saúde do trabalhador. R Saúde Pública [Internet]. 1991 [citado 2015 nov. 08];5(25):341-9. Disponível em: https://www.nescon.medicina.ufmg.br/biblioteca/ imagem/2977.pdf.

2. IV Conferência Estadual de Saúde do Trabalhador e Trabalhadora. Relatório final [Internet]. 30 jun-02 jul 2014; Gravatá. Recife: Secretaria do Estado de Pernambuco; 2014 [citado 2016 abr. 2016]. Disponível em: http://portal.saude.pe.gov.br/sites/portal.saude.pe.gov.br/files/relatorio final iv conferencia estadual de saude do trabalhador.pdf

3. Minayo-Gomez CC, Thedim-Costa SMF. A construção do campo da saúde do trabalhador: percurso e dilemas. Cad Saúde Pública [Internet]. 1997 [citado 2015 set. 23];13(supl. 2):S21-S32. Disponível em: http://www.scielosp.org/scielo.php?script=sci arttext\&pid=S0102311X1997000600003\&lng=en\&nrm=isso

4. Gurgel AM. Uso do coque verde de petróleo como matriz energética em Pernambuco e a perspectiva da vigilância em saúde: Estudo de caso no Complexo Industrial Portuário de Suape [dissertação on line]. Recife: Fundação Oswaldo Cruz; Centro de Pesquisas Aggeu Magalhães; 2011 [citado 2016 set. 2015]. Disponível em: http://www.cpqam.fiocruz.br/bibpdf/2011gurgel-am.pdf.

5. Brasil. Ministério da Saúde. Secretaria de Políticas de Saúde. Departamento de Atenção Básica. Área Técnica de Saúde do Trabalhador Saúde do trabalhador. Cadernos de Atenção Básica. Programa Saúde da Família Caderno 5. Saúde do Trabalhador. Brasília; 2001. [citado 08 nov. 2015]. Disponível em: http://bvsms.saude.gov.br/bvs/publicacoes/cd03 12.pdf.

6. Teixeira SF. Reforma sanitária: em busca de uma teoria. São Paulo: Cortez; 1989.

7. Dias EC. A atenção à saúde dos trabalhadores no setor saúde (SUS), no Brasil: realidade, fantasia ou utopia [tese on line]. Campinas: Universidade Estadual de Campinas; 1994 [citado 2015 nov. 08]. Disponível em: http://www.bibliotecadigital.unicamp.br/document/?code=000082078.

8. Brasil. Constituição da República Federativa do Brasil [Internet]. Diário Oficial da União, Brasília (DF). 1988; Seção 1:1 [citado 25 nov. 2016]. Disponível em: http://www.planalto.gov.br/ccivil 03/ Constituicao/Constituicao.htm.

9. Brasil. Lei no 8.080 de 19 de setembro de 1990. Dispõe sobre as condições para promoção, proteção e recuperação da saúde, a organização e o financiamento dos serviços correspondentes e dá outras providências [Internet]. Diário Oficial da União, Brasília (DF). 1990; Seção 1:18055 [citado 25 nov. 2016]. Disponível em: http://www.planalto.gov.br/ccivil 03/leis/L8080.htm.

10. Brasil. Decreto no 7.508, de 28 de junho de 2011. Regulamenta a Lei no 8.080, de 19 de setembro de 1990, para dispor sobre a organização do Sistema Único de Saúde - SUS, o planejamento da saúde, a assistência à saúde e a articulação interfederativa, e dá outras providências [Internet]. Diário Oficial da União, Brasília (DF). 2011; Seção 1:1 [citado 2016 nov. 25]. Disponível em: http://www2.camara.leg.br/ legin/fed/decret/2011/decreto-7508-28-junho-2011-610868-norma-pe.html.

11. Brasil. Ministério da Saúde. Portaria no 2.135, de 25 de setembro de 2013. Estabelece diretrizes para o processo de planejamento no âmbito do Sistema Único de Saúde (SUS) [Internet]. Diário Oficial da União, Brasília (DF). 2013; Seção 1:60 [citado 2016 nov. 25]. Disponível em: http://bvsms.saude.gov.br/ bvs/saudelegis/gm/2013/prt2135 2509 2013.html.

12. Chorny AH. Planificación em salud: viejas índias em nuevos ropajes. Cuad Méd Soc [Internet]. 1998 mayo [citado 2015 nov. 08];73:23-44. Disponível em: http://www.buenosaires.gob.ar/areas/salud/ dircap/mat/matbiblio/chorny.pdf.

13. Brasil. Ministério da Saúde. Organização Pan-Americana da Saúde. Sistema de planejamento do SUS (PlanejaSUS): uma construção coletiva: trajetória e orientações de operacionalização [Internet]. Brasília; 2009 [citado 2015 nov. 20]. Disponível em: http://bvsms.saude.gov.br/bvs/publicacoes/planejaSUS livro 1a6.pdf.

14. Brasil. Lei complementar 131, de 27 de maio de 2009. Acrescenta dispositivos à Lei Complementar $n^{0}$ 101 , de 4 de maio de 2000, que estabelece normas de finanças públicas voltadas para a responsabilidade na gestão fiscal e dá outras providências, a fim de determinar a disponibilização, em tempo real, de informações pormenorizadas sobre a execução orçamentária e financeira da União, dos Estados, do Distrito Federal e dos Municípios [Internet]. Diário Oficial da União, Brasília (DF). 2009; Seção 1:2 [citado 2016 maio 20]. Disponível em: http://www.planalto.gov.br/ccivil 03/leis/LCP/Lcp131.htm. 
15. Brasil. Lei Complementar $n^{\circ} 141$, de 13 de janeiro de 2012. Regulamenta o § 30 do art. 198 da Constituição Federal para dispor sobre os valores mínimos a serem aplicados anualmente pela União, Estados, Distrito Federal e Municípios em ações e serviços públicos de saúde; estabelece os critérios de rateio dos recursos de transferências para a saúde e as normas de fiscalização, avaliação e controle das despesas com saúde nas 3 (três) esferas de governo; revoga dispositivos das Leis nos 8.080, de 19 de setembro de 1990, e 8.689, de 27 de julho de 1993; e dá outras providências [Internet]. Diário Oficial da União, Brasília (DF). 2012; Seção 1:1 [citado 2016 maio 20]. Disponível em: http://www.planalto.gov. br/ccivil 03/leis/LCP/LCp141.htm.

16. Brasil. Ministério da Saúde. Portaria n 399, de 22 de fevereiro de 2006. Divulga o pacto pela Saúde 2006 - Consolidação do SUS e aprova as diretrizes operacionais do referido pacto [Internet]. Diário Oficial da União, Brasília (DF). 2006; Seção 1:43 [citado 2016 maio 20]. Disponível em: http://bvsms. saude.gov.br/bvs/saudelegis/gm/2006/prt0399 2202 2006.html.

17. Brasil. Lei no 8.142, de 28 de dezembro de 1990. Dispõe sobre a participação da comunidade na gestão do Sistema Único de Saúde (SUS) e sobre as transferências intergovernamentais de recursos financeiros na área da saúde e dá outras providências [Internet]. Diário Oficial da União, Brasília (DF). 1990; Seção 1:25.694. Disponível em: http://www.planalto.gov.br/ccivil 03/leis/L8142.htm

18. Pernambuco. Assembleia Legislativa do Estado de Pernambuco. Constituição do Estado de Pernambuco [Internet]. Recife, 1989 [citado 2016 nov. 28]. Disponível em: http://legis.alepe.pe.gov.br/arquivoTexto. aspx?tiponorma $=12 \&$ numero $=1989 \&$ complemento $=0 \& a n o=1989 \&$ tipo $=\&$ url $=$.

19. Pernambuco. Decreto no 20.786, de 10 de agosto de 1998. Altera o Regulamento do Código Sanitário do Estado de Pernambuco [Internet]. Recife, 1998 [citado 2016 nov. 28]. Disponível em: http://www. progeal.com.br/site/wp-content/uploads/2011/05/C\%C3\%B3digo-Sanit\%C3\%A1rio-de-Pernambuco.pdf.

20. Mélo LA. Os caminhos da política nacional de saúde do trabalhador em Pernambuco [dissertação on line]. Recife: Universidade Federal de Pernambuco; Programa de Pós-Graduação Integrado em Saúde Coletiva; 2013 [citado 25 jan. 2016]. Disponível em: http://repositorio.ufpe.br/ handle/123456789/13959.

21. Brasil. Portaria no 2.728, de 11 de novembro de 2009. Dispõe sobre a Rede Nacional de Atenção Integral à Saúde do Trabalhador (RENAST) e dá outras providências [Internet]. Diário Oficial da União, Brasília (DF). 2009; [citado 2016 nov. 28] Seção 1:76. Disponível em: http://bvsms.saude.gov.br/bvs/ saudelegis/gm/2009/prt2728 1111 2009.html.

22. Pernambuco. Secretaria de Saúde do Estado de Pernambuco. Comissão Intergestores Bipartite. Resolução CIB/PE 2.613, de 21 de julho de 2014. Institui a Regionalização dos Centros de Referência em Saúde do Trabalhador no Estado de Pernambuco [Internet]. Diário Oficial do Estado de Pernambuco. 2014 [citado 2016 nov. 28]; 91:142. Disponível em: http://portal.saude.pe.gov.br/sites/portal.saude. pe.gov.br/files/resol 2613 regionalizacao cerest- saude do trabalhador.pdf.

23. Francisco WCE. A economia do estado de Pernambuco [Internet]. São Paulo: Brasil Escola; 2013 [citado 2016 jan 25]. Disponível em: http://brasilescola.uol.com.br/brasil/a-economia-estado-pernambuco.htm.

24. Pernambuco. Governo do Estado de Pernambuco. Mapa da VI Região de Saúde de Pernambuco. Arcoverde; 2012.

25. Brasil. Ministério da Saúde. Portaria no 1.823, de 23 de agosto de 2012. Dispõe sobre a Política Nacional de Saúde do Trabalhador e da Trabalhadora [Internet]. Diário Oficial da União, Brasília (DF). 2012 [citado 2016 jan 25]; Seção 1:46. Disponível em: http://bvsms.saude.gov.br/bvs/saudelegis/gm/2012/

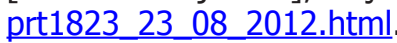

26. Brasil. Ministério da Saúde. Sistema de Apoio ao Relatório de Gestão Sargsus [Internet]. Brasília; 2016 [citado 2016 nov. 28]. Disponível em: www.saude.gov.br/sargsus

27. Saliba NA, Garbin CAS, Gonçalves PE, Santos JG, Souza P, Moimaz SAS. Plano Municipal de Saúde: análise do instrumento de gestão [Internet]. Bioscience J 2013 jan.-fev. [citado 2016 abr. 15];29(1):224-30. Disponível em: http://www.seer.ufu.br/index.php/biosciencejournal/article/ download/15054/1199111991.

28. Brasil. Ministério da Saúde. Manual de planejamento no SUS [Internet]. Brasília; 2015 [citado 2016 nov. 28]. (Série Articulação Interfederativa; v. 4). Disponível em: http://www.saude.rs.gov.br/ upload/1454600684 Manual\%20Planejamento\%20SUS.pdf. 
29. Vaz FCA, Cunha TC, Oliveira DC. Dificuldades na implementação das ações em saúde do trabalhador pelo Sistema Único de Saúde. R Interdisciplinar NOVAFAPI [Internet]. 2011 out.-dez. [citado 2016 maio 04];4(4):61-5. Disponível em: http://www.novafapi.com.br/sistemas/revistainterdisciplinar/v4n4/revisao/ rev2 v4n4.pdf.

30. Daldon M TB, Lancman S. Vigilância em saúde do trabalhador: rumos e incertezas. R Bras Saúde Ocupacional [Internet]. 2013 jun. [citado 2016 maio 04];38(127):92-106. Disponível em: http://www. scielo.br/scielo.php?script=sci arttext\&pid=S0303-76572013000100012\&lng=en.

31. Brasil. Decreto-Lei no 5452, de 1 de maio de 1943. Aprova a consolidação das leis do trabalho [Internet]. Diário Oficial da União, Brasília (DF). 1943 [citado 2016 jan. 25];Seção 1:11937. Disponível em: http://www.planalto.gov.br/ccivil 03/decreto-lei/Del5452compilado.htm.

32. Albuquerque PCC, Gurgel IGD, Gurgel AM, Augusto LGS, Siqueira MT. Sistemas de informação em saúde e as intoxicações por agrotóxicos em Pernambuco. R Bras Epidemiol [Internet]. 2015 set. [citado 2016 abr.15];18(3):666-78. Disponível em: http://www.scielo.br/scielo.php?script=sci arttext\&pid=S1415790X2015000300666\&lng=pt.

33. Cavalcante CAA, Santos RS, Cavalcante EFO, Martins RL, Silveira EA, Silva ET. Perfil dos agravos relacionados ao trabalho notificados no Rio Grande do Norte, 2007 a 2009. Epidemiol Serv Saúde [Internet]. $2014 \mathrm{dez}$ [citado 2016 abr.18];23(4):741-52. Disponível em: http://scielo.iec.pa.gov.br/scielo. php?script=sci arttext\&pid=S1679-49742014000400016\&lng=pt.

34. Brasil. Portaria no 1.271, de 6 de junho de 2014. Define a lista nacional de notificação compulsória de doenças, agravos e eventos de saúde pública nos serviços de saúde públicos e privados em todo o território nacional, nos termos do anexo, e dá outras providências [Internet]. Diário Oficial da União, Brasília (DF). 2014 [citado 2016 nov. 28];Seção 1:67-9. Disponível em: http://bvsms.saude.gov.br/bvs/ saudelegis/gm/2014/prt1271 0606 2014.html.

35. Teixeira HV, Teixeira MG. Financiamento da saúde pública no Brasil: a experiência do Siops. Ci. Saúde Coletiva [Internet]. 2003 [citado 2016 abr. 21];8(2):379-91. Disponível em: http://www.scielo.br/scielo. php?script $=$ sci $\quad$ arttext\&pid $=$ S1413-81232003000200005\&lng=pt

36. Baratieri T, Vecchia ACGD, Pilger C. A gestão da saúde do trabalhador nos municípios da $5^{2}$ regional de saúde do Paraná. Reas [Internet]. 2012[citado 2016 abr. 06]1(1):57-9. Disponível em: http://www.uftm. edu.br/revistaeletronica/index.php/enfer/article/view/279/278.

37. Portaria MTB no 3.214, de 08 de junho de 1978. Aprova as Normas Regulamentadoras - NR - do capítulo V, título II, da Consolidação das Leis do Trabalho, relativas a Segurança e Medicina do Trabalho Norma Regulamentadora 6 - Nr 6 Equipamento de Proteção Individual - EPI [Internet]. [citado 2016 nov. 28]. Disponível em: http://www.guiatrabalhista.com.br/legislacao/nr/nr6.htm

38. Brasil. Ministério da Saúde. Resolução CNS no 493, de 07 de novembro de 2013. Resolve que os Conselhos de Saúde nos âmbitos Estadual, Distrital e Municipal promovam a criação da Comissão Intersetorial de Saúde do Trabalhador - CIST, por meio de resolução para assessorar ao Plenário do referido Conselho resgatando e reiterando os princípios do SUS e do controle social. Brasília; 2013. Disponível em: http://renastonline.ensp.fiocruz.br/recursos/resolu\%C3\%A7\%C3\%A3o-n\%C2\%BA-4937-novembro-2013-cria\%C3\%A7\%C3\%A3o-comiss\%C3\%A3o-sa\%C3\%BAde-trabalhador-cist.

39. Barros ME, Piola SF, Vianna SM. 1996. Políticas de Saúde no Brasil, Diagnóstico e Perspectivas [Internet]. Brasília: IPEA; 1996 [citado 2016 abr. 20]. (Texto para Discussão; 401). Disponível em: http://repositorio.ipea.gov.br/bitstream/11058/1835/1/td 0401.pdf

40. Dias MDA, Bertolini GCS, Pimenta AL. Saúde do trabalhador na atenção básica: análise a partir de uma experiência municipal. Trab Educ Saúde [Internet]. 2011 [citada 2016 nov. 20];9(1):137-48. Disponível em: http://www.scielo.br/pdf/tes/v9n1/v9n1a10.pdf 